\title{
Death-associated protein kinase 1 has a critical role in aberrant tau protein regulation and function
}

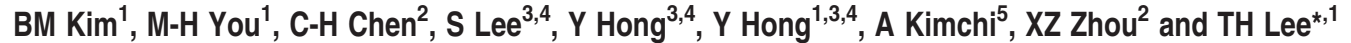

The presence of tangles composed of phosphorylated tau is one of the neuropathological hallmarks of Alzheimer's disease (AD). Tau, a microtubule (MT)-associated protein, accumulates in AD potentially as a result of posttranslational modifications, such as hyperphosphorylation and conformational changes. However, it has not been fully understood how tau accumulation and phosphorylation are deregulated. In the present study, we identified a novel role of death-associated protein kinase 1 (DAPK1) in the regulation of the tau protein. We found that hippocampal DAPK1 expression is markedly increased in the brains of AD patients compared with age-matched normal subjects. DAPK1 overexpression increased tau protein stability and phosphorylation at multiple AD-related sites. In contrast, inhibition of DAPK1 by overexpression of a DAPK1 kinase-deficient mutant or by genetic knockout significantly decreased tau protein stability and abolished its phosphorylation in cell cultures and in mice. Mechanistically, DAPK1-enhanced tau protein stability was mediated by Ser71 phosphorylation of Pin1, a prolyl isomerase known to regulate tau protein stability, phosphorylation, and tau-related pathologies. In addition, inhibition of DAPK1 kinase activity significantly increased the assembly of MTs and accelerated nerve growth factor-mediated neurite outgrowth. Given that DAPK1 has been genetically linked to late onset AD, these results suggest that DAPK1 is a novel regulator of tau protein abundance, and that DAPK1 upregulation might contribute to tau-related pathologies in AD. Therefore, we offer that DAPK1 might be a novel therapeutic target for treating human AD and other tau-related pathologies.

Cell Death and Disease (2014) 5, e1237; doi:10.1038/cddis.2014.216; published online 22 May 2014

Subject Category: Neuroscience

Tau-related pathology (tauopathy) is involved in neurodegenerative diseases, including Alzheimer's disease (AD) and related disorders. ${ }^{1-4}$ In these diseases, tau is commonly hyperphosphorylated on serine or threonine residues prior to tangle formation and neurodegeneration. ${ }^{5-7}$ Tau helps stabilize the microtubule (MT) network in neurons, ${ }^{8-11}$ and aberrant tau phosphorylation disrupts its MT function ${ }^{12-14}$ and alters its protein stability. ${ }^{15-19}$ In all tauopathies, aberrantly phosphorylated tau adopts abnormal conformations and aggregates into neurofibrillary tangles (NFTs). ${ }^{5-7}$ The significance of tau phosphorylation is further supported by the findings that tau kinase ${ }^{20-22}$ or phosphatases ${ }^{23,24}$ are deregulated in $\mathrm{AD}$ and that their modulation can affect tauopathies. ${ }^{25-27}$ However, how tau accumulation and phosphorylation are deregulated in neurodegenerative diseases, such as $A D$, is not fully understood.

Death-associated protein kinase 1 (DAPK1), a death domain-containing calcium/calmodulin-regulated serine/ threonine kinase, functions as a positive mediator of apoptosis. ${ }^{28}$ DAPK1 overexpression promotes neuronal cell death, and neurons lacking DAPK1 are less susceptible to apoptotic insults in cell culture and knockout (KO) animal models. ${ }^{28}$ Furthermore, DAPK1 regulates tau toxicity by modulating MT assembly and neuronal differentiation, ${ }^{29}$ and influences brain damage via the $\mathrm{N}$-methyl-D aspartate receptor in stroke. ${ }^{30}$ Moreover, genome-wide association study showed that two gene-centric single-nucleotide polymorphisms in the DAPK1 are strongly associated with lateonset $A D .^{31,32}$ Indeed, mice expressing DAPK1 kinase domain deletions showed enhanced learning and spatial memory compared with wild-type (WT) mice. ${ }^{33}$ However, the association between DAPK1 and late-onset AD has not been sufficiently explored, as little is known about the downstream targets of DAPK1 in $A D$, and DAPK1 regulation in $A D$ progression is poorly understood.

We showed previously that DAPK1 phosphorylates Ser71 in the catalytic active site of Pin1, thereby inhibiting its cellular function. ${ }^{34}$ Pin1, a unique peptidyl-prolyl cis-trans isomerase, is an enzyme that has a critical role in regulating a subset of phosphoproteins by specifically catalyzing conformational change on the phosphorylated Ser/Thr-Pro motifs. ${ }^{35,36}$ In line with its diverse physiological role, Pin1 has been linked to the

\footnotetext{
${ }^{1}$ Division of Gerontology, Department of Medicine, Beth Israel Deaconess Medical Center, Harvard Medical School, Boston, MA, USA; ${ }^{2}$ Division of Hematology/ Oncology, Department of Medicine, Beth Israel Deaconess Medical Center, Harvard Medical School, Boston, MA, USA; ${ }^{3}$ Department of Rehabilitation Science, Graduate School of Inje University, Gimhae, Korea; ${ }^{4}$ Cardiovascular \& Metabolic Disease Center, College of Biomedical Science \& Engineering, Inje University, Gimhae, Korea and ${ }^{5}$ Department of Molecular Genetics, Weizmann Institute of Science, Rehovot, Israel

${ }^{*}$ Corresponding author: Dr TH Lee, Division of Gerontology, Department of Medicine, Beth Israel Deaconess Medical Center, Harvard Medical School, Room DA 519 A, 330 Brookline Avenue, Boston, MA 02215, USA. Tel: +1 617667 0091; Fax: +1 617667 0102; E-mail: tlee3@ @idmc.harvard.edu

Keywords: death-associated protein kinase 1 (DAPK1); Alzheimer's disease; tau stability; Pin1; tau phosphorylation; tau-related pathology

Abbreviations: AD, alzheimer's disease; DAPK1, death-associated protein kinase 1; MT, microtubule; NFTs, neurofibrillary tangles; WT, wild-type; KO, knockout; sh-RNAs, small hairpin RNAs; si-RNAs, small interfering RNAs; MARK, microtubule-affinity regulating kinase; MEF, mouse embryonic fibroblast; CHX, cycloheximide; NGF, nerve growth factor; PFA, paraformaldehyde; S.E., standard error

Received 22.1.14; revised 03.4.14; accepted 14.4.14; Edited by N Bazan
} 
pathogenesis of various human diseases, including $A D$, Parkinson disease, cancer, and asthma. ${ }^{35,36}$ Moreover, Pin1 has an important protective role in the brain against $A D$ by maintaining tau and amyloid precursor protein in their proper forms. ${ }^{37-40}$ Pin 1 is also colocalized with phosphorylated tau in AD brain and other tauopathies. ${ }^{41}$ It binds to and isomerizes the pThr231-Pro motif in tau to restore its ability to bind MTs and to promote their assembly. ${ }^{40}$ Therefore, loss of Pin1 function can lead to abnormal tau protein accumulation and MT disintegration, which are the main features of $A D$. Although DAPK1 inhibits the tumorigenic properties of Pin1, it is not known whether DAPK1 regulates Pin1 function during neurodegeneration.

In this study, we found that DAPK1 enhanced tau stability and phosphorylation, thereby inhibiting its cellular function. Furthermore, we showed that DAPK1-dependent tau regulation might be mediated by Pin1 Ser71 phosphorylation and subsequent inactivation. Taken together, these results demonstrate for the first time a potential role for DAPK1 in the regulation of tau accumulation and function in neurodegenerative diseases, including AD.

\section{Results}

DAPK1 expression is highly upregulated in human AD hippocampus. As DAPK1 polymorphisms are associated with $A D$ susceptibility, ${ }^{31,32}$ we first investigated potential association between late onset $A D$ and DAPK1 expression. Considering DAPK1 expression is restricted to the hippocampus of the adult brain, ${ }^{42}$ hippocampal DAPK1 levels were measured in a cohort of 12 AD patients and 12 age-matched normal subjects. The expression of DAPK1 was found to increase more than two-fold in the AD patients compared with that of normal subjects (Figures 1a and b). Moreover, phosphorylated Thr231 or Ser396 of tau was highly overexpressed in the brains of AD patients, as describe previously (Figure 1a). ${ }^{12,43}$ DAPK1 mRNA levels were also increased in AD brains compared with normal brains, but this difference was not statistically significant, implying that DAPK1 upregulation in AD is a consequence of increased translation and/or stability of the DAPK1 protein (Figure 1c). Thus, these results showed that in human AD brains DAPK1 was upregulated, and this might be correlated with tau phosphorylation.

DAPK1 increases tau protein expression and stability in cells. To examine whether DAPK1 contributes to agedependent neurodegeneration in $A D$ via tau regulation, we determined the effect of DAPK1 on tau protein expression. DAPK1 significantly increased exogenous tau protein levels compared with the vector control (Figure 2a). We further examined tau protein expression using DAPK1 mutants, which have been characterized previously. ${ }^{44} \mathrm{DAPK} 1^{\mathrm{K} 42 \mathrm{~A}}$, a kinase-deficient mutant, downregulated, whereas DAPK $1^{\Delta \mathrm{CaM}}$, a constitutively active mutant, upregulated exogenous tau protein expression compared with the vector control (Figure 2a). Endogenous tau expression was assessed in human neuroblastoma SH-SY5Y cells transfected with the vector control, DAPK1, DAPK1 ${ }^{\mathrm{K} 42 \mathrm{~A}}$, or a

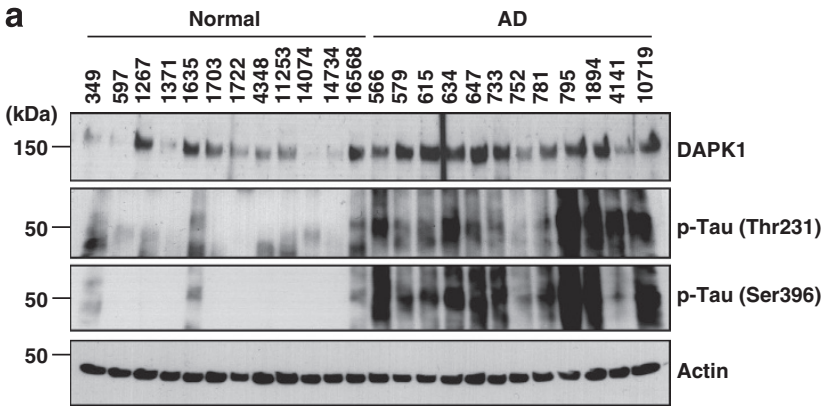

b

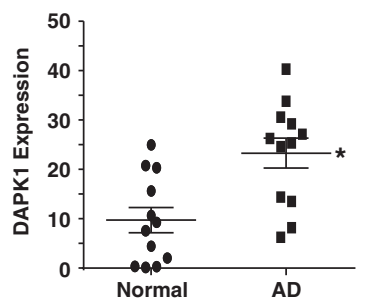

C

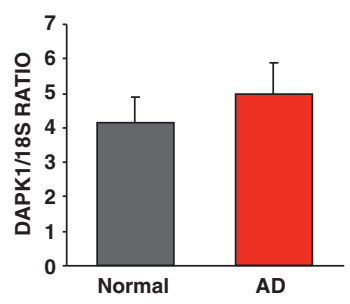

Figure 1 DAPK1 expression is increased in the AD patient brain. Hippocampal tissues of $12 \mathrm{AD}$ patients and 12 age-matched controls were harvested. (a) Proteins from normal and AD hippocampus were used for immunoblot with anti-DAPK1, antipT231-Tau, anti-pS396-Tau, or anti-actin antibody. The blots are representative of three independent experiments. (b) DAPK1 intensities were quantified by computerassisted densitometry ( ${ }^{*} P<0.05$ versus normal control; ANOVA/Dunnett's test). (c) Quantitative RT-PCR was performed on CDNA samples to measure human DAPK1 mRNA. Eight AD and six normal brain samples with short PMI $(<20 \mathrm{~h})$ were used to minimize possible RNA degradation. 18S ribosomal RNA was used as an endogenous control. Each data point represents the mean \pm S.E. of three independent experiments

DAPK $1^{\triangle \mathrm{CaM}}$ and was found to be upregulated in DAPK1and DAPK $1^{\triangle \mathrm{CaM}}$-expressing cells compared with the vector control- or DAPK $1^{\mathrm{K} 42 \mathrm{~A}}$-expressing cells (Figure $2 \mathrm{~b}$ ). Similar trends were observed in another neuroblastoma cell line, SK-N-SH (Supplementary Figure 1). Next, we efficiently knocked down the expression of endogenous DAPK1 using lentiviral-mediated small hairpin RNAs (sh-RNAs) or small interfering RNAs (si-RNAs) in the SH-SY5Y cells (Figures 2c and d). In contrast with the control cells, endogenous tau expression was decreased dramatically in DAPK1 knockdown cells (Figures $2 \mathrm{c}$ and $\mathrm{d}$ ). However, there was no increase in tau mRNA levels after overexpression of DAPK1 or DAPK $1^{\mathrm{K} 42 \mathrm{~A}}$ (Figure $2 \mathrm{e}$ ), suggesting that DAPK1 does not affect tau at the level of transcription but rather at the protein level. Thus, DAPK1 increases exogenous and endogenous tau protein expression in cells.

Given that DAPK1 increased tau protein levels but not transcription, the next question was whether DAPK1 might affect tau protein stability. The exogenous- and endogenous tau protein were quite stable in cells expressing DAPK1 or $\mathrm{DAPK} 1^{\triangle \mathrm{CaM}}$ but not DAPK $1^{\mathrm{K} 42 \mathrm{~A}}$, compared with cells expressing the vector control (Figures $3 a, b$, e and $f$ ). We also used lentiviral expression systems to generate NIH3T3 cells expressing DAPK1 in a tetracycline-inducible manner, as described: ${ }^{34}$ the addition of the tetracycline analoge, doxycycline, into the growth medium resulted in the production of DAPK1 (Supplementary Figure 2). Doxycycline-induced expression of DAPK1 efficiently enhanced tau protein stability compared with the vector control (Figures $3 c$ and $d$ ). 
a

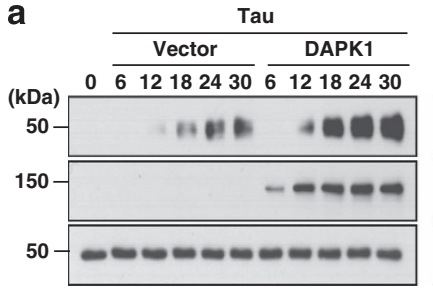

b

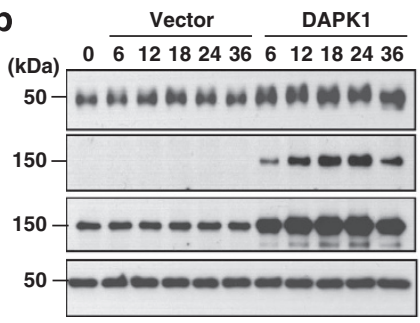

d

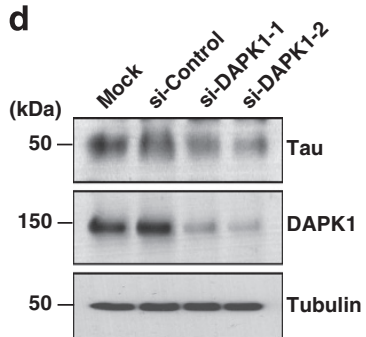

Tau

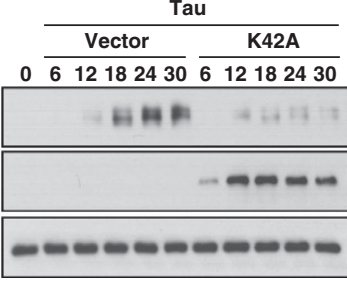

Vector K42A $\triangle$ CaM

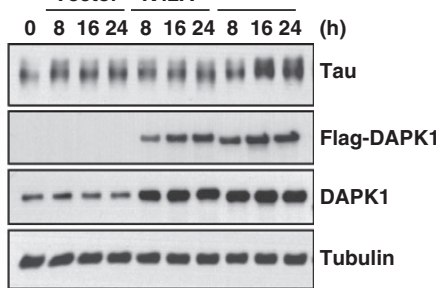

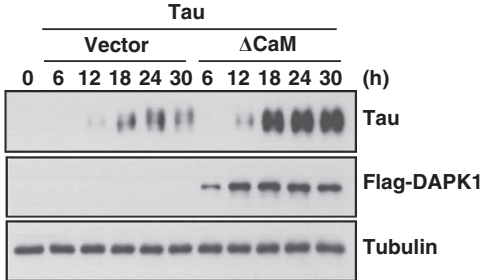

C

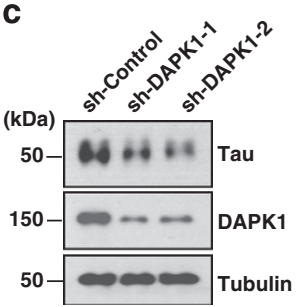

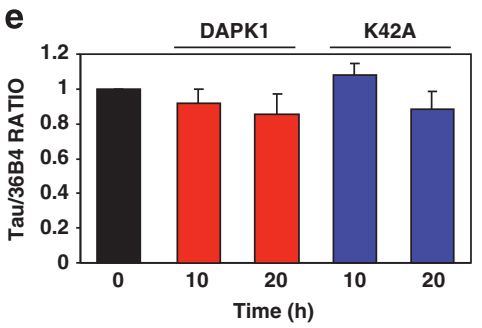

Figure 2 DAPK1 increases tau protein expression in cell culture models. (a) HeLa cells were co-transfected with pcDNA3-Tau and either pRK5-Flag, pRK5-Flag-DAPK1, pRK5-Flag-DAPK $1^{\mathrm{K} 42 \mathrm{~A}}$ or pRK5-Flag-DAPK $1^{\Delta \mathrm{CaM}}$ for the indicated times. The cell lysates were subjected to western blot analysis with anti-Tau-5 or anti-tubulin antibody. The blots are representative of three independent experiments. (b) SH-SY5Y cells were transfected with pRK5-Flag, pRK5-Flag-DAPK1, pRK5-Flag-DAPK1 ${ }^{\mathrm{K} 42 \mathrm{~A}}$ or pRK5-FlagDAPK ${ }^{\Delta \mathrm{CaM}}$ for the indicated times. The cell lysates were subjected to western blot analysis with anti-Tau- 5 or anti-tubulin antibody. The blots are representative of three independent experiments. (c) SH-SY5Y cells were infected with control lentiviral vector (pLKO.1) or vectors encoding two DAPK1-specific sh-RNAs, and selected using puromycin $(1.5 \mu \mathrm{g} / \mathrm{ml})$ for $36 \mathrm{~h}$. The cell lysates were subjected to western blot analysis with anti-Tau-5 or anti-tubulin antibody. The blots are representative of three independent experiments. (d) SH-SY5Y cells were transfected with two different human DAPK1-sepcific si-RNAs or scrambled control si-RNA for $36 \mathrm{~h}$. The cell lysates were subjected to western blot analysis with anti-Tau-5 or anti-tubulin antibody. The blots are representative of three independent experiments. (e) SH-SY5Y cells were transfected with pRK5-Flag, pRK5-Flag-DAPK1, or pRK5-Flag-DAPK1 ${ }^{\mathrm{K} 42 \mathrm{~A}}$ for $24 \mathrm{~h}$. Quantitative RT-PCR was performed on cDNA samples to measure human tau mRNA, and the $36 \mathrm{~B} 4$ gene was used as an endogenous control. Each data point represents the mean \pm S.E. of three independent experiments

Altogether, these results suggest that DAPK1 overexpression inhibits tau protein turnover in cells.

DAPK1 regulates tau stability through Thr231 phosphorylation. Recent studies by our group and others reported that Pin1 regulates tau phosphorylation, protein stability, function and tauopathy ${ }^{37,38,40}$ and that DAPK1 negatively regulates Pin1 activity through Ser71 phosphorylation. ${ }^{34}$ It was also shown that the MT-affinity regulating kinase (MARK) $1 / 2$ is activated by DAPK1 to phosphorylate tau on Ser262, regulating its toxicity. ${ }^{29}$ To examine whether DAPK1-enhanced tau stability is dependent upon the inhibition of Pin1 and/or the activation of MARK1/2, we generated tau point mutations, tau ${ }^{\mathrm{T} 231 \mathrm{~A}}$, which is unable to bind Pin1, and tau ${ }^{\mathrm{S} 262 \mathrm{~A}}$, which is resistant to MARK1/2 phosphorylation. When the T231A tau mutant was cotransfected with DAPK1 or the vector control, tau ${ }^{\mathrm{T} 231 \mathrm{~A}}$ expression levels were not increased in DAPK1-expressing cells compared with the vector control (Figure 4a). Moreover, the stability of T231A tau protein was not affected by either DAPK1 or DAPK $1^{\mathrm{K} 42 \mathrm{~A}}$ (Figures $4 \mathrm{~b}$ and $\mathrm{c}$ ), suggesting that Pin1 action on phosphorylated Thr231 is necessary for
DAPK1-regulated tau protein stability. However, expression and stability of the S262A protein were increased by DAPK1 expression, but not by DAPK $1^{\mathrm{K} 42 \mathrm{~A}}$, compared with the vector control (Figures $4 d-f$ ), similar to the results with the WT tau protein. These results indicate that MARK proteins are not involved in the effects of DAPK1 on tau protein stability. Taken together, our data show that DAPK1 regulates tau protein expression and stability, presumably through tau Thr231 and Pin1 phosphorylation.

DAPK1 increases tau protein stability by inhibiting Pin1 function. We further investigated the role of Pin1 by examining tau protein turnover using DAPK1 KO and Pin1 $\mathrm{KO}$ mouse embryonic fibroblast (MEF) cells, which were confirmed for the absence of DAPK1 and Pin1 protein, respectively (Supplementary Figure 3 ). When we transfected WT tau into DAPK1 KO or WT MEF cells, the exogenous tau protein was less stable in DAPK1 KO than in WT MEF cells (Figures $5 \mathrm{a}$ and b). However, when we co-transfected tau with vector control or DAPK1 into Pin1 KO MEF cells, exogenous tau protein stability did not increase in DAPK1-transfected cells compared with vector controls 
a

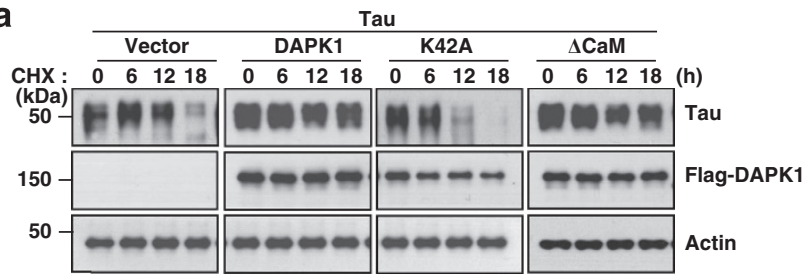

C

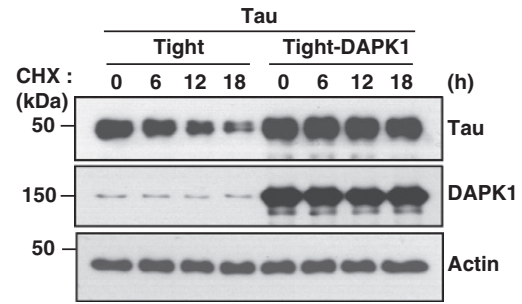

e

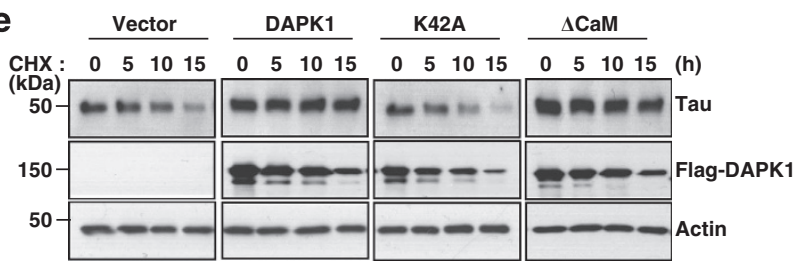

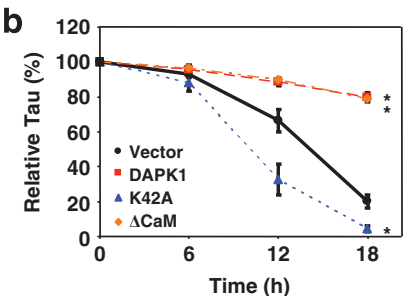

d
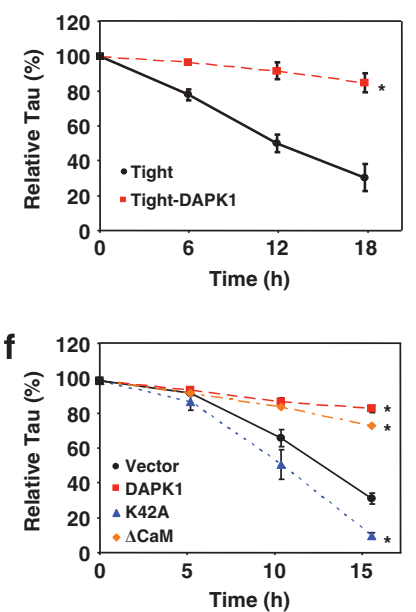

Figure 3 DAPK1 increases tau protein stability in cell culture models. (a, b) HeLa cells were co-transfected with pcDNA3-Tau and either pRK5-Flag, pRK5-Flag-DAPK1, pRK5-Flag-DAPK1 ${ }^{\mathrm{K} 42 \mathrm{~A}}$ or pRK5-Flag-DAPK ${ }^{\Delta \mathrm{CaM}}$ for $20 \mathrm{~h}$ followed by treatment with $10 \mu \mathrm{g} / \mathrm{ml} \mathrm{CHX}$ for the indicated times. The cell lysates were subjected to western blot analysis with anti-Tau- 5 or anti-actin antibody. The blots are representative of three independent experiments, and data shown represent means $\pm S$. E. of three independent experiments $\left({ }^{*} P<0.05\right.$ versus vector-expressing control; ANOVA/Dunnett's test). (c, d) NIH3T3 cells stably expressing pTRE-Tight vector or pTRE-Tight-DAPK1 were transfected with pcDNA3-Tau for $8 \mathrm{~h}$ followed by treatment with $2 \mu \mathrm{g} / \mathrm{ml}$ doxycycline for $14 \mathrm{~h}$. Doxycycline-induced cells were treated with $25 \mu \mathrm{g} / \mathrm{ml} \mathrm{CHX}$ for the indicated times. The cell lysates were subjected to western blot analysis with anti-Tau-5, anti-DAPK1 or anti-actin antibody. The blots are representative of three independent experiments, and data shown represent means \pm S.E. of three independent experiments ( ${ }^{*} P<0.05$ versus Tight-vector-expressing control; ANOVA/Dunnett's test). (e, f) SK-N-SH cells were transfected with pRK5-Flag, pRK5-Flag-DAPK1, pRK5-Flag-DAPK1 ${ }^{\mathrm{K} 42 \mathrm{~A}}$ or pRK5-Flag-DAPK1 ${ }^{\Delta \mathrm{CaM}}$ for $20 \mathrm{~h}$ followed by treatment with $75 \mu \mathrm{g} / \mathrm{ml} \mathrm{CHX}$ for the indicated times. The cell lysates were subjected to western blot analysis with anti-Tau- 5 or anti-actin antibody. The blots are representative of three independent experiments, and data shown represent means $\pm S$.E. of three independent experiments ( ${ }^{\star} P<0.05$ versus vector-expressing control; ANOVA/Dunnett's test)
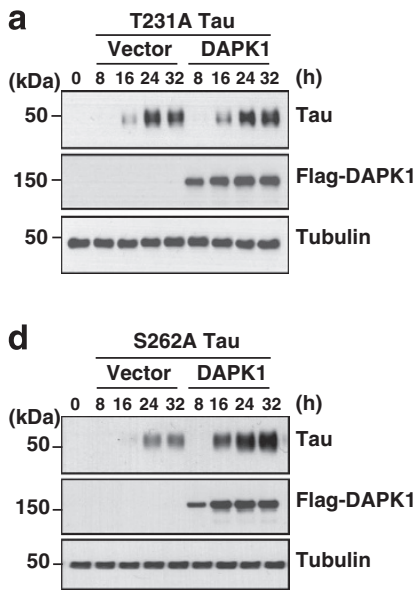
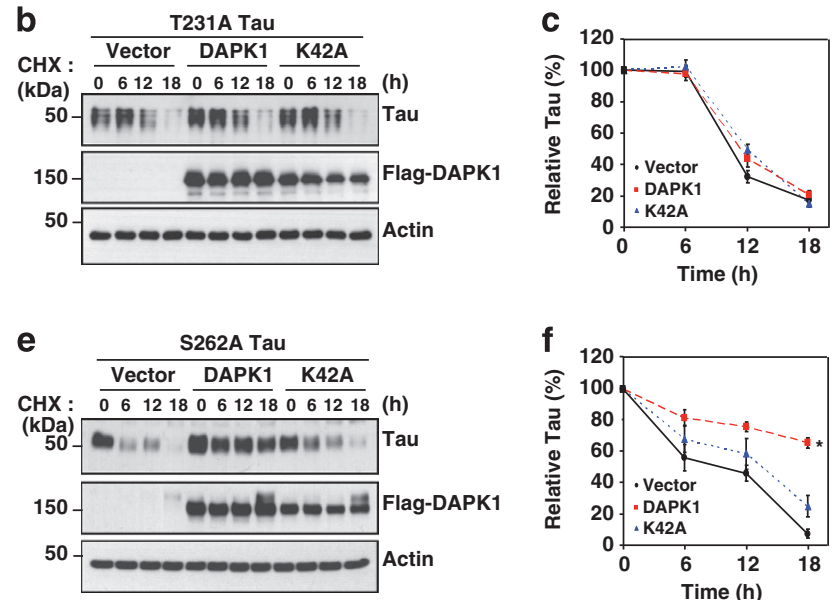

Figure 4 Effects of DAPK1 on protein stability of tau T231A and S262A mutants. (a, d) HeLa cells were co-transfected with pcDNA3-T231A tau and either pRK5-Flag or pRK5-Flag-DAPK1 (a) or co-transfected with pcDNA3-S262A tau and either pRK5-Flag or pRK5-Flag-DAPK1 (d) for the indicated times. The cell lysates were subjected to western blot analysis with anti-Tau-5 or anti-tubulin antibody. The blots are representative of three independent experiments. (b, $\mathbf{c}, \mathbf{e}, \mathbf{f})$ HeLa cells were co-transfected with pcDNA3-T231A tau and either pRK5-Flag, pRK5-Flag-DAPK1 or pRK5-Flag-DAPK1 ${ }^{\text {K42A }}(\mathbf{b}, \mathbf{c})$ or co-transfected with pcDNA3-S262A tau and either pRK5-Flag, pRK5-FlagDAPK1 or pRK5-Flag-DAPK1 ${ }^{K 42 A}$ (e, f) for $20 \mathrm{~h}$ followed by treatment with $10 \mu \mathrm{g} / \mathrm{ml} \mathrm{CHX}$ for the indicated times. The cell lysates were subjected to western blot analysis with anti-Tau- 5 or anti-actin antibody. The blots are representative of three independent experiments, and data shown represent means $\pm S$.E. of three independent experiments $\left({ }^{\star} P<0.05\right.$ versus vector-expressing control; ANOVA/Dunnett's test) 
a

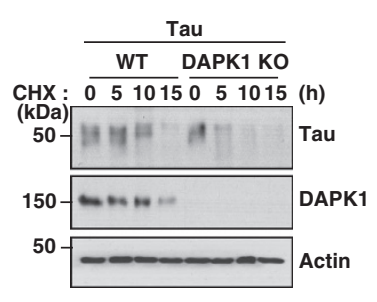

C

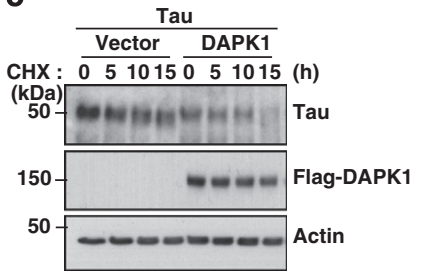

b

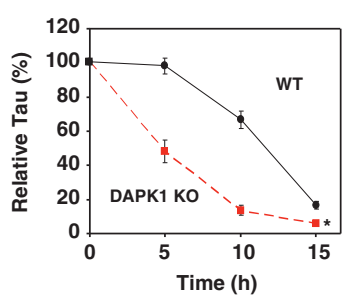

d

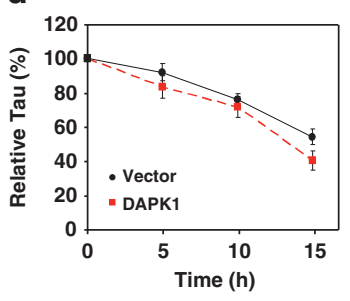

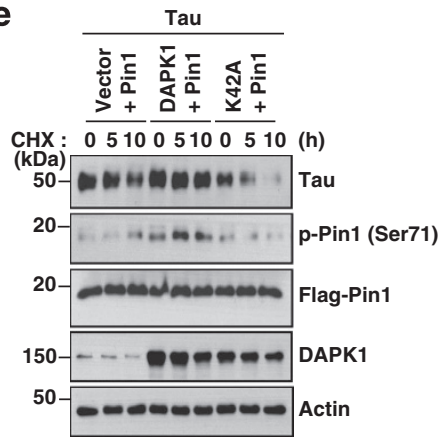

f

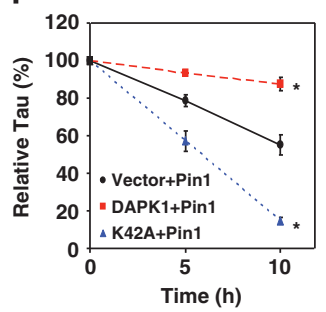

Figure 5 DAPK1 increases tau protein stability through the inhibitory phosphorylation of Pin1. (a, b) MEF cells from WT and DAPK1 KO mice were transfected with pcDNA3-Tau for $20 \mathrm{~h}$ followed by treatment with $25 \mu \mathrm{g} / \mathrm{ml} \mathrm{CHX}$ for the indicated times. The cell lysates were subjected to western blot analysis with anti-Tau-5 or anti-actin antibody. The blots are representative of three independent experiments, and data shown represent means \pm S.E. of three independent experiments ( ${ }^{*} P<0.05$ versus WT; ANOVA/Dunnett's test). (c, d) MEF cells from Pin1 KO mice were co-transfected with pcDNA3-Tau and either pRK5-Flag or pRK5-Flag-DAPK1 for $20 \mathrm{~h}$ followed by treatment with $25 \mu \mathrm{g} / \mathrm{ml} \mathrm{CHX}$ for the indicated times. The cell lysates were subjected to western blot analysis with anti-Tau-5 or anti-actin antibody. The blots are representative of three independent experiments. (e, f) NIH3T3 cells stably expressing Flag-Pin1 in combination with doxycycline-inducible expression of pTRE-Tight ('Vector + Pin1') or pTRE-TightDAPK1 ('DAPK1 + Pin1') or pTRE-DAPK1 ${ }^{\mathrm{K} 42 \mathrm{~A}}$ ('K42A + Pin1') were transfected with pcDNA3-Tau for $8 \mathrm{~h}$ and subsequently induced with $2 \mu \mathrm{g} / \mathrm{ml}$ doxycycline for an additional $14 \mathrm{~h}$ followed by treatment with $25 \mu \mathrm{g} / \mathrm{ml} \mathrm{CHX}$ for the indicated times. The cell lysates were subjected to western blot analysis with anti-Tau-5, anti-Flag, anti-pSer71Pin1, or anti-actin antibody. The blots are representative of three independent experiments, and data shown represent means \pm S.E. of three independent experiments $\left({ }^{*} P<0.05\right.$ versus vector + Pin 1 -expressing control; ANOVA/Dunnett's test)

(Figures $5 \mathrm{c}$ and $\mathrm{d}$ ). In addition, sh-RNA-mediated stable knockdown of Pin1 also abrogated DAPK1-enhanced tau stability in HeLa cells (Supplementary Figure 4), indicating that Pin1 has an important role in DAPK1-mediated tau protein regulation. Next, to determine whether DAPK1 inhibits tau turnover by Pin1, we used NIH3T3 cells stably expressing Pin1 and tetracycline-inducible DAPK1, $\mathrm{DAPK} 1^{\mathrm{K} 42 \mathrm{~A}}$ or the vector control as shown previously. ${ }^{34}$ Tau protein stability and Pin1 Ser71 phosphorylation were significantly increased in cells expressing DAPK1/Pin1, but not DAPK $1{ }^{\mathrm{K} 42 \mathrm{~A}} / \mathrm{Pin} 1$, compared with the vector control/Pin1expressing cells (Figures $5 e$ and $\mathrm{f}$ ). As Pin1 may promote tau degradation, these results suggest that DAPK1 acts as a central regulator of tau protein stability via Pin1 inhibition.

DAPK1 KO mice show reduced tau protein expression and stability. We next examined the effects of DAPK1 on tau protein expression and stability in the brains of agematched WT and DAPK1 KO mice at different ages. Whereas levels of doublecortin (DCX), an established neurogenesis marker, decreased with age in both mouse models, the expression of DAPK1 was not affected in WT mice (Figure 6a). We next evaluated endogenous tau protein expression in these mice. Whereas there was no significant difference in tau expression between 1- and 6-month-old WT and $\mathrm{KO}$ mice (Figure 6b), it was significantly decreased in 12and 22-month-old DAPK1 KO mice compared with WT mice of the same age (Figures $6 b$ and $c$ ). There were no significant differences in mouse tau mRNA levels between WT and DAPK1 KO mice at 12 or 22 months (Figure 6d), confirming the results shown in Figure $2 \mathrm{e}$. These findings suggest that DAPK1 KO downregulates tau protein expression in an age-dependent manner in the mouse brain.

Next, we examined whether DAPK1 affects tau protein stability in brain tissues. In primary cortical neurons, the halflife of endogenous mouse tau was $\sim 20 \mathrm{~h}$ in the presence of DAPK1 but was decreased significantly to $<3 \mathrm{~h}$ in the absence of DAPK1 (Figures 6e and f). Moreover, phosphorylation of Pin1 on Ser71 was also higher in cortical neurons from WT mice than those from DAPK1 KO mice (Figure 6e), suggesting that DAPK1-mediated Pin1 phosphorylation is correlated with tau stability. In brain slices from 1-month-old WT and DAPK1 KO mice, the half-life of tau was $\sim 20 \mathrm{~h}$ in the presence of DAPK1 and was decreased dramatically to $\sim 6 \mathrm{~h}$ in the absence of DAPK1 (Figures $6 g$ and $h$ ). We obtained the same results in brain slices from 6-month-old mice (Supplementary Figure 5). Thus, these results showed that DAPK1 enhanced endogenous tau stability in primary cortical neurons as well as brain-slice cultures, an in situ model resembling and retaining many organizational features of living brain tissue.

DAPK1 affects tau phosphorylation in an age-dependent manner. Tau protein is aberrantly phosphorylated, adopts 
a

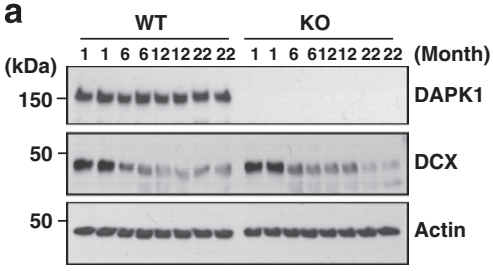

e

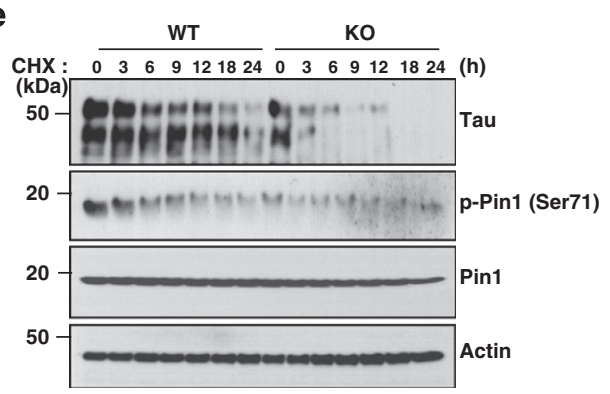

b

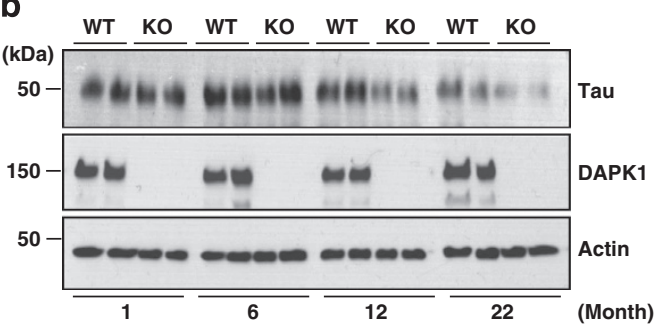

f

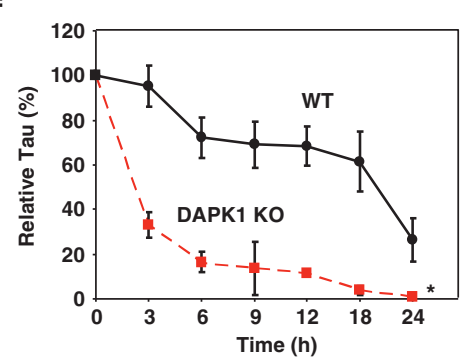

C

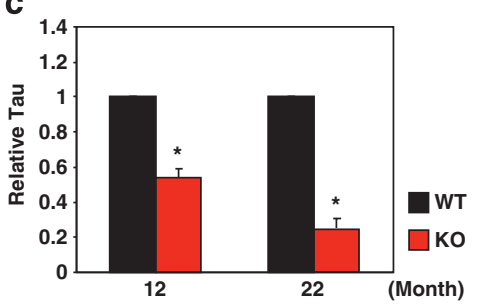

d

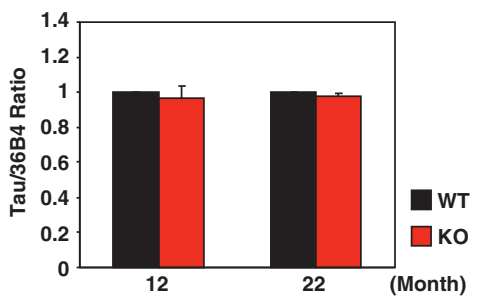

g

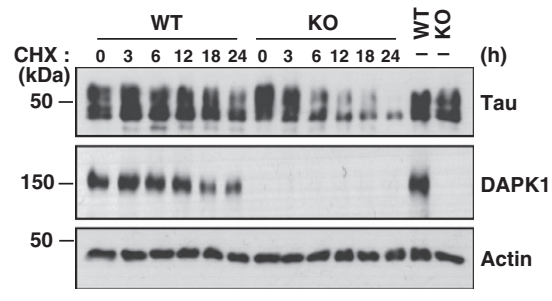

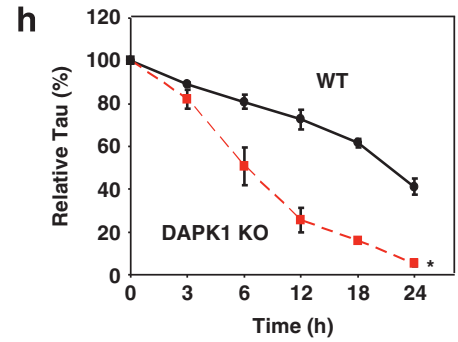

Figure 6 DAPK1 KO reduces tau protein expression and stability in mouse brain. (a) Whole-brain lysates from mice harvested at the indicated age (in months) were analyzed for DAPK1 levels. (b) The brain tissues were homogenized and subjected to western blot analysis with anti-Tau-5 or anti-actin antibody. (c) Densitometric analysis of normalized levels of tau using actin as a loading control obtained from 12- and 22-month-old mice. (d) Six brain tissue sections of WT and DAPK1 KO mice, 12- or 22-monthold, were harvested. Quantitative RT-PCR was performed on cDNA samples to measure mouse tau mRNA, and the $36 \mathrm{~B} 4$ gene was used as an endogenous control. (e, f) Primary cortical cultures derived from the cerebral cortex of embryonic day 16 (E16) WT and DAPK1 KO mice were treated $25 \mu \mathrm{g} / \mathrm{ml}$ of CHX for indicated times. Cells were lysed and subjected soluble protein lysates to western blot analysis with anti-Tau-5, anti-Pin1, anti-pSer71-Pin1, or anti-actin antibody. (g, h) Brain tissue slices of $260 \mu \mathrm{m}$ were prepared and cultured from WT or DAPK1 KO mice at 1 month of age. $35 \mu \mathrm{g} / \mathrm{ml}$ of CHX was added and chased for indicated times. Some brain tissue slices were cultured for $24 \mathrm{~h}$ without $\mathrm{CHX}$ to monitor structural integrity (last 2 columns). Brain slices were lysed and subjected soluble protein lysates to western blot analysis with anti-Tau-5 or anti-actin antibody. All of above blots are representative of three independent experiments, and data shown represent means \pm S.E. of three independent experiments $\left({ }^{*} P<0.05\right.$ versus WT; ANOVA/Dunnett's test)

abnormal conformations, and aggregates into fibrils during all tauopathies, including AD. ${ }^{5-7}$ As shown in Figure $7 \mathrm{a}$, compared with the vector control, DAPK1, but not $\mathrm{DAPK} 1^{\mathrm{K} 42 \mathrm{~A}}$, increased the phosphorylation of exogenous tau protein in HeLa cells, as detected by Thr231-specific (AT180), Ser262-specific, and Ser396-specific (PHF-13) antibodies that recognize specific tau phosphoepitopes and/or abnormal conformations specific to AD NFT. DAPK1 also triggered the phosphorylation of endogenous tau protein in SH-SY5Y cells (Figure 7b). Moreover, DAPK1 induced Ser71 phosphorylation of Pin1 compared with cells transfected with the empty vector or DAPK $1^{\mathrm{K} 42 \mathrm{~A}}$, suggesting that enhanced expression and phosphorylation of tau in DAPK1expressing cells was due to phosphorylation of Pin1 (Figures $7 \mathrm{a}$ and b). Thus, DAPK1 overexpression, but not the kinase-deficient mutant $\mathrm{K} 42 \mathrm{~A}$, increased tau phosphorylation in cells.

The effect of DAPK1 ablation on phosphorylation of tau and Pin1 in mouse brain tissue was evaluated using immunoblotting with AT180, pSer262-specific, PHF-13, and pSer71-Pin1 antibodies. DAPK1 KO significantly decreased the levels of tau phosphorylation as well as Pin1 phosphorylation in the brains of DAPK1 KO mice at age 12-22 months, but not those at age 6 month, compared with WT littermates (Figure 7c). The inhibitory effects of DAPK1 ablation on tau phosphorylation were also observed when we analyzed the sarkosyl-insoluble fraction. Total and phosphorylated tau levels were barely detectable in the sarkosyl-insoluble fraction at 6 month, but mildly expressed at 12-22 months of age in WT mice (Figure 7d). However, levels of total and phosphorylated tau were significantly reduced in DAPK1 KO mice at 12-22 months of age compared with those in WT mice (Figure 7d). Our immunohistochemical staining also confirmed that DAPK1 ablation reduced pThr231-Tau and pSer71-Pin1 levels in mouse brain sections (Figures 7e and f). Thus, our results indicate that DAPK1 KO dramatically decreased tau phosphorylation in whole-brain lysates and inhibited tau-related pathological phenotypes such as NFT 
a

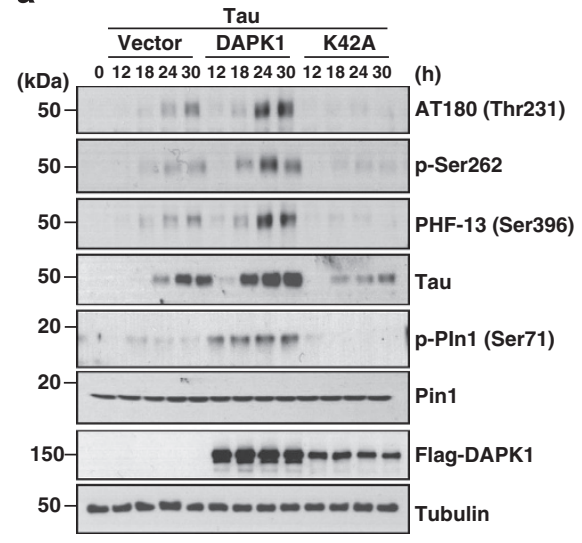

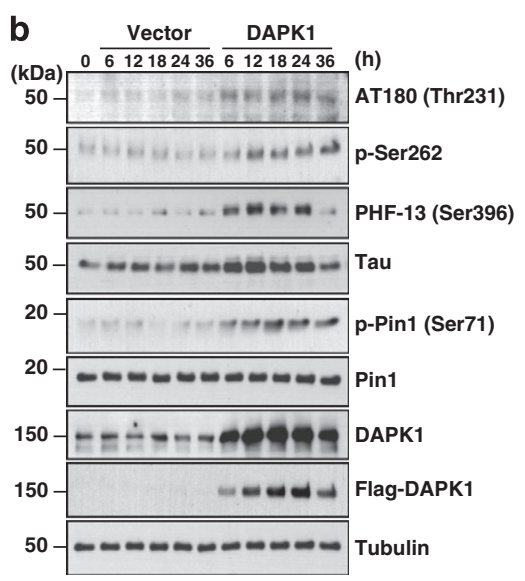

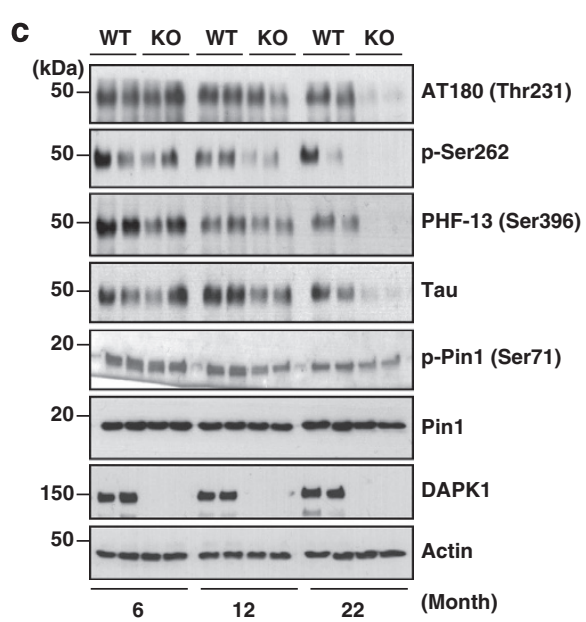

d

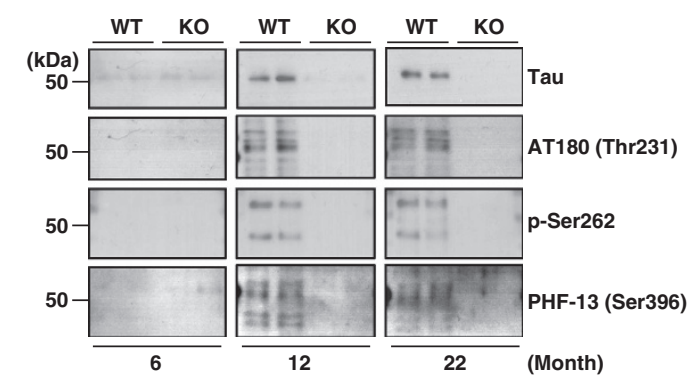

e
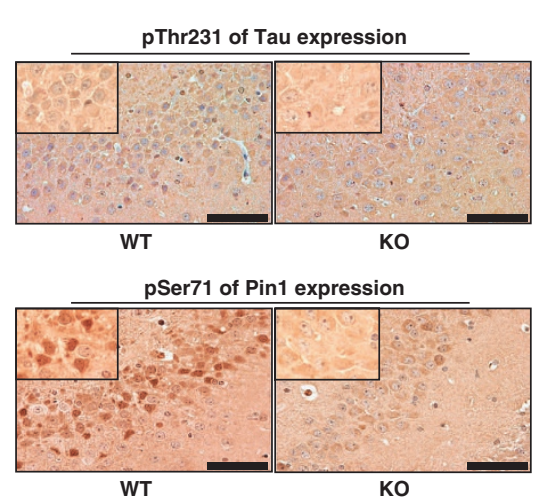

f

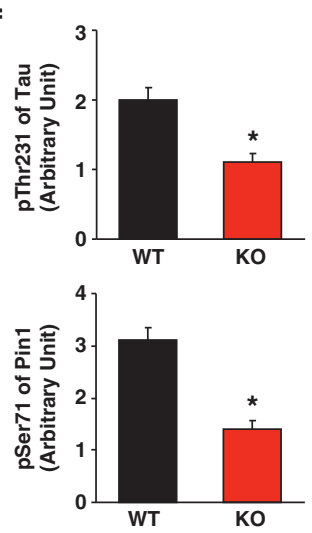

Figure 7 DAPK1 increases tau phosphorylation and formation of sarkosyl-insoluble tau aggregates. (a) HeLa cells were co-transfected with pcDNA3-Tau and either pRK5-Flag, pRK5-Flag-DAPK1, or pRK5-Flag-DAPK1 ${ }^{\text {K }}{ }^{2 A}$ for the indicated times. The cell lysates were subjected to western blot analysis for the phosphorylation of exogenous tau protein. Anti-tubulin antibody was used as a loading control. The blots are representative of three independent experiments. (b) SH-SY5Y cells were transfected with pRK5-Flag or pRK5-Flag-DAPK1 for the indicated times. The cell lysates were subjected to western blot analysis for the phosphorylation of endogenous tau protein. Anti-tubulin antibody was used as a loading control. The blots are representative of three independent experiments. (c, d) The whole-cell lysates (c) and sarkosylinsoluble fractions (d) were subjected to western blot analysis. Phospho-specific tau antibodies (AT180, Ser262 and PHF-13) were used to detect tau phosphorylation. The blots are representative of three independent experiments. (e, f) Immunohistochemistry of paraffin-embedded brain sections from WT and DAPK1 KO mice at 24-month-old, comparing the levels of phosphorylated tau (Thr231) and phosphorylated Pin1 (Ser71). Original magnification, $\times 40$ (main photographs); $\times 60$ (insets); Scale bar $=100 \mu \mathrm{m}$. The images are representative of three independent experiments, and data shown represent means \pm S.E. of three independent experiments ( ${ }^{*} P<0.05$ versus WT; ANOVA/Dunnett's test)

conformations in sarkosyl-insoluble fraction in an agedependent manner in the mouse brain model.

DAPK1 inhibits neurite outgrowth and MT assembly. Tau has an important role in regulating MT dynamics ${ }^{8-11}$ and neuronal differentiation, ${ }^{45}$ which are modulated by sitespecific phosphorylation. ${ }^{46}$ Considering the effects of DAPK1 on Pin1-mediated tau protein stability and phosphorylation, we addressed the biological significance of DAPK1 on tau function by assaying neurite outgrowth and MT assembly. Inhibition of DAPK1 using either novel selective DAPK1 inhibitor $\left(\mathrm{IC}_{50}=69 \mathrm{nM}\right)$ or RNA interference significantly increased NGF-induced neurite outgrowth in PC12 cells (Figures 8a-e, Supplementary Figure 6) and enhanced maturation of primary mouse cortical neurons (Supplementary Figure 7). As the primary function of tau is modulation of cytoskeletal MT stability and function, ${ }^{8-11}$ and abnormal tau phosphorylation results in disruption of MT organization, ${ }^{12-14}$ we also investigated the effect of DAPK1 on MT organization. DAPK1 inhibitor significantly increased the protein levels of polymerized tubulin showing similar effects induced by MT-stabilizing paclitaxel (Figures $8 f$ and g). However, MT-disrupting nocodazole caused inhibition of tubulin polymerization (Figures $8 \mathrm{f}$ and $\mathrm{g}$ ). Therefore, our results suggest that DAPK1 inhibits neuronal differentiation and MT polymerization by affecting tau functions.

\section{Discussion}

Although there are several current evidence for a role of DAPK1 in neurodegenerative disorders, ${ }^{29,31-33}$ little has been known about the molecular mechanisms through which DAPK1 exerts this effect. Here, we show that DAPK1 is associated with tau-mediated neuronal degeneration by enhancing tau stability and aberrant phosphorylation, leading to deregulation of its MT binding and polymerization functions. Enhanced protein stability and/or decreased degradation of tau trigger its aggregation, which inhibits neuronal cell survival 


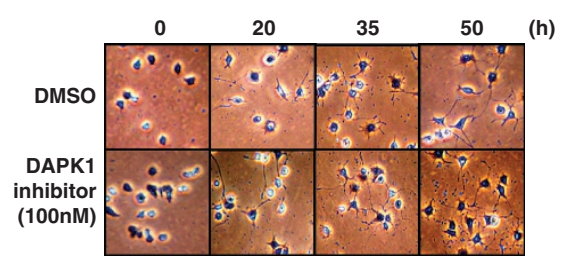

c

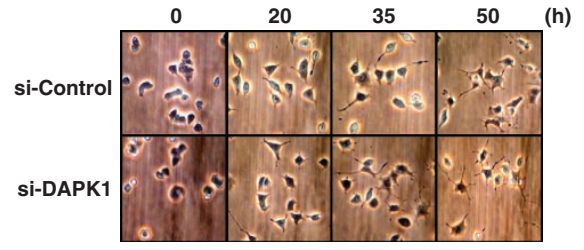

b

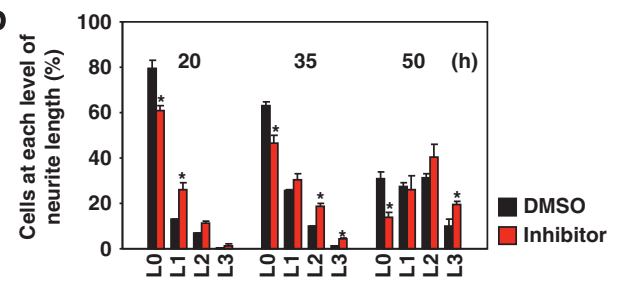

d

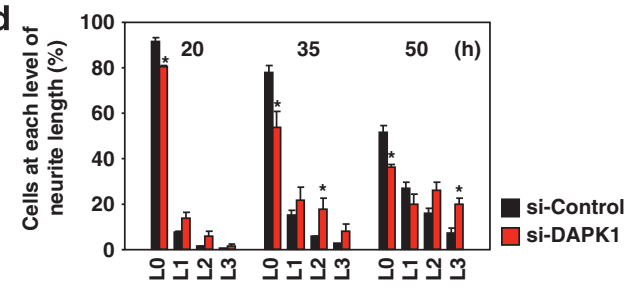

e

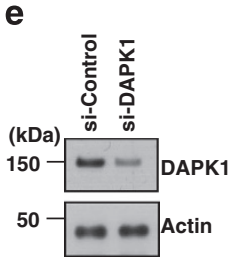

f

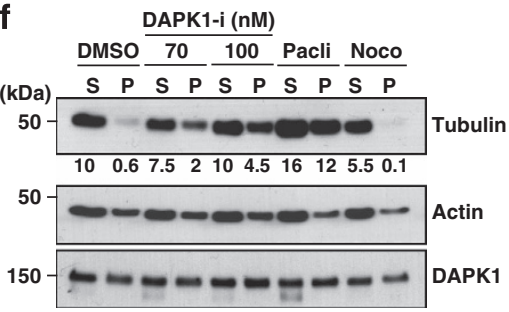

g

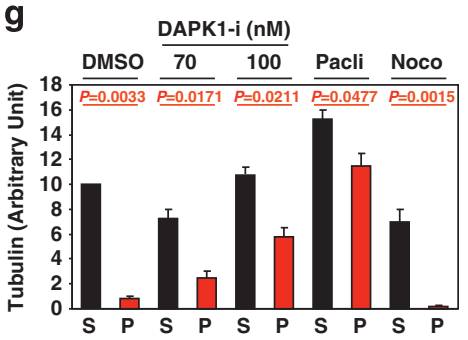

Figure 8 DAPK1 inhibits neurite outgrowth and MT assembly. (a, b) After serum starvation ( $0.5 \%$ horse serum and $0.25 \%$ FBS) for $12 \mathrm{~h}$, PC12 cells were pretreated with $100 \mathrm{nM}$ DAPK1 inhibitor for $2 \mathrm{~h}$ prior to the co-treatment with NGF (50 ng/ml). After NGF treatment for up to $50 \mathrm{~h}$, the level of neurite outgrowth was quantified by counting the number of PC12 cells bearing neurites and measuring the neurite length in ten random images from triplicate experiments. The representative images are shown, and data represent means \pm S.E. of three independent experiments ( ${ }^{*} P<0.05$ versus DMSO; ANOVA/Dunnett's test). Distribution of the neurite length was quantified as described in the 'Materials and Methods' section. (c, d) PC12 cells were transfected with rat DAPK1 si-RNA or scrambled si-RNA for $36 \mathrm{~h}$ and serum-deprived for $12 \mathrm{~h}$ followed by NGF $(50 \mathrm{ng} / \mathrm{ml})$ treatment. After NGF treatment for up to $50 \mathrm{~h}$, the level of neurite outgrowth was quantified as described in Figure $8 \mathrm{~b}$. The representative images are shown, and data represent means $\pm S$.E. of three independent experiments ( ${ }^{*} P<0.05$ versus si-Control; ANOVA/Dunnett's test). (e) The efficiency of a si-RNA-mediated knockdown of DAPK1 in PC12 cells. (f, g) PC12 cells were treated with the vehicle (DMSO), paclitaxel ( $0.2 \mu \mathrm{M}$, Pacli), nocodazole ( $2 \mu \mathrm{M}$, Noco) or DAPK1 inhibitor (70-, $100 \mathrm{nM}$ ) for $12 \mathrm{~h}$ and then lysed with hypotonic buffer. Equal amounts of cytosolic (S, soluble) and cytoskeletal (P, polymerized) proteins were separated by SDS-PAGE and immunoblotted with anti-tubulin antibody. Tubulin expression level at DMSO-treated cytosolic/soluble fraction was arbitrarily defined as '10'. The representative blots are shown, and data represent means \pm S.E. of three independent experiments. Statistical differences between the level of soluble and polymerized tubulin in each treatment were also determined

and induces neurodegeneration. ${ }^{12-16,18,19}$ Several proteins have been known to regulate tau protein stability. For example, Pin1 knockdown and/or downregulation in $A D$ neurons increase tau protein stability. ${ }^{38}$ As DAPK1 was shown to inhibit Pin1 catalytic activity and function, ${ }^{34}$ DAPK1 could affect tau via Pin1 inhibition in neurons.

Our greatest interest was in the potential association between late onset $A D$ and DAPK1 expression, as DAPK1 polymorphisms are associated with $A D$ susceptibility. ${ }^{31,32} \mathrm{We}$ measured DAPK1 expression in the hippocampus of $A D$ patients and normal controls, as the hippocampus is damaged early and severely in AD compared with other parts of the cortex and DAPK1 expression is restricted to the hippocampus of the adult brain. ${ }^{42}$ We found that hippocampal tissues from aged AD brains had increased levels of DAPK1 protein relative to age-matched normal subjects.

We found that the DAPK1 significantly enhanced tau protein expression and stability in cell culture and mouse brain models. Moreover, DAPK $1^{\mathrm{K} 42 \mathrm{~A}}$, a kinase-deficient DAPK1 mutant, could not enhance tau protein stability, suggesting that DAPK1 kinase activity is critical for tau protein stability. It was shown that the levels of neurofilament (NF) protein are increased significantly in $A D^{47,48}$ and that WW domain-containing oxidoreductase (WWOX) is downregulated in the neurons of $A D$ hippocampi. ${ }^{49}$ Interestingly, DAPK1 had no effect on the NF light chain (NF-L) but significantly downregulated WWOX protein levels (data not shown), which remains to be further elucidated.

Abnormal phosphorylation of tau is considered to be one of the earliest events in neuronal degeneration and appears to precede tau aggregation. ${ }^{5-7}$ This abnormal phosphorylation results not only in a toxic loss of function, such as decreased MT binding, but also a toxic gain of function, such as increased tau-tau interaction and pathological aggregation of PHFs. ${ }^{46}$ Phosphorylation can also alter the stability and proteotoxicity of tau. ${ }^{15,16,18,19}$ In cell cultures, DAPK1, but not the kinasedeficient mutant K42A, increased tau phosphorylation at Thr231, Ser262, and Ser396. These results were confirmed in the mouse brain model, suggesting that DAPK1 KO decreased tau phosphorylation at AD-related sites. Interestingly, the expression of total and phosphorylated tau in DAPK1 KO mouse brain decreased in an age-dependent manner with changes more prominent in 12- to 22-month-old mice. The sarkosyl-insoluble fractions were enriched for 
abnormal fibrils and phosphorylated tau. ${ }^{50}$ Sarkosyl-insoluble tau, which provides a measure for abnormal tau aggregation, ${ }^{51}$ was barely detected in 6-month-old WT mouse brains and was found in moderate levels in 12- to 22-month-old mice. Both phosphorylated and total tau levels in the sarkosylinsoluble fraction were significantly reduced in DAPK1 KO mice compared with WT littermates. These results suggest that DAPK1 is involved in the pathological transition from the normal soluble to the filamentous insoluble form of tau.

Given that aberrant tau phosphorylation disrupts its MT function $^{12-14}$ and DAPK1 affected tau phosphorylation, DAPK1 potentially alters tau-MT interaction. We showed that inhibition of DAPK1 promoted NGF-induced neurite outgrowth, a major indicator of overall nervous system cellular health. Tau drives neurite outgrowth and elongation by promoting the assembly of tubulin into $\mathrm{MT},{ }^{8-11}$ which are critical for the establishment of neuronal cell polarity. ${ }^{8,52}$ Our results also demonstrated that the inhibition of DAPK1 kinase activity led to an increased assembly of tubulin into MTs, suggesting that DAPK1 suppresses neurite outgrowth and MT assembly via abnormal phosphorylation of tau.

Pin1 has a pivotal role in protection against neurodegeneration by restoring the conformation and function of phosphorylated tau or by promoting its dephosphorylation. ${ }^{36-38,40}$ One of our primary interests was the involvement of Pin1 in DAPK1-mediated tau protein regulation, as it was shown that DAPK1 phosphorylated Ser71 in the catalytic site and inhibited the cellular function of Pin1. ${ }^{34}$ DAPK1-mediated increase in tau protein expression and stability were accompanied by increased Pin1 Ser71 phosphorylation. DAPK1 did not increase the stability of the T231A tau mutant, which was also unaffected by Pin1. In a similar fashion, DAPK1 did not affect tau protein stability in Pin1 KO MEF cells. These results are in line with immunohistochemical data showing that the expression of Ser71 phosphorylated Pin1 was significantly lower in DAPK1 KO mouse brain compared with WT mouse brain. Altogether, these data suggest that DAPK1 regulates tau protein via inhibitory phosphorylation of Pin1.

Recently, Wu et $a^{29}$ reported that MARK1/2 is important in DAPK1-mediated MT assembly and tau toxicity. Ser262 of tau is the most important residue phosphorylated by MARK2 for MT dynamics ${ }^{53,54}$ and that phosphorylation of this residue is enhanced in $A D$, which may have a role in tangle formation. ${ }^{55,56}$ The interaction between MARK2 and tau has also been investigated extensively. ${ }^{56}$ We demonstrated that the protein expression and stability of the S262A tau mutant, which inhibits the interaction between MARK2 and tau, were significantly increased by DAPK1, similar to that of WT tau, suggesting that DAPK1-enhanced tau protein stability is independent of MARK proteins.

As tau accumulation is a critical event in tauopathy, our demonstration of the critical role of DAPK1 in tau accumulation substantiates the need for further studies on its effects on tauopathy. Such an effort would benefit from the generation of transgenic $(\mathrm{Tg})$ mice with inducible and brain-restricted DAPK1 expression or of DAPK1 KO/ Tg mice crossed with tauopathy mouse models. Because $A D$ is an irreversible and progressive brain disease, slowing its progression is currently the best option, underscoring the importance of early diagnosis and therapeutic intervention for improving treatment outcome. Even though we detected increased DAPK1 expression in the brains of AD patients, it has not yet been determined whether it is a reliable biological diagnostic marker for the incipient stages of AD. Standard laboratory testing, such as blood tests, combined with the newly developed and state-of-the-art brain molecular imaging techniques used to detect brain pathological biomarkers will facilitate investigation of this possibility.

Taken together, our findings suggest that DAPK1 enhances tau protein stability and that DAPK1 KO might abolish abnormal phosphorylation and aggregation of tau. We also found that DAPK1 triggered Pin1 Ser71 phosphorylation in a neuronal model, and DAPK1-mediated regulation of tau protein was prevented in the absence of Pin1, suggesting a critical role for Pin1. The functional studies showed that DAPK1 is involved in the impairment of normal cellular tau function, including MT assembly. Furthermore, our results also demonstrated that DAPK1 expression is increased in AD brains and may be a marker of AD pathology. Overall, our data suggest a model in which DAPK1 inhibits tau function via aberrant tau phosphorylation/accumulation followed by impaired tau-MT interactions and promote pathological tau aggregation through inhibitory phosphorylation of Pin1 (Supplementary Figure 8). Moreover, our studies suggest that DAPK1 represents a potential novel therapeutic approach for human $A D$ and other tauopathies.

\section{Materials and Methods}

Materials. Cycloheximide (CHX), N-lauroylsarcosine Sodium Salt, nerve growth factor (NGF), paclitaxel, nocodazole, and paraformaldehyde (PFA) were purchased from Sigma (St. Louis, MO, USA). DAPK1 inhibitor (4Z)-4-(3Pyridylmethylene)-2-styryl-oxazol-5-one was obtained from Calbiochem (Billerica, MA, USA). CHX was used to inhibit protein synthesis and assess tau protein stability. The alkyl anionic detergent $N$-lauroylsarcosine sodium salt was used to obtain sarkosyl-insoluble fraction. NGF was used to stimulate neurite outgrowth. Paclitaxel was used to stabilize MT, and Nocodazole was used to disrupt MT. (4Z)-4-(3-Pyridylmethylene)-2-styryl-oxazol-5-one was used to specifically inhibit DAPK1 kinase activity.

Cell culture. The human cervix carcinoma cell line HeLa; the human neuroblastoma cell lines SH-SY5Y and SK-N-SH; the mouse fibroblast cell line NIH3T3; and the rat pheochromocytoma cell line PC12 were obtained from the American Type Culture Collection. MEF cells were obtained from the WT, DAPK1 $\mathrm{KO}$, and Pin1 KO embryos between embryonic day 12.5 and 14.5. HeLa, SH-SY5Y, SK-N-SH, NIH3T3, and MEF cells were cultured in high-glucose Dulbecco's modified Eagle's medium (DMEM) supplemented with $10 \%$ fetal bovine serum (FBS), $100 \mathrm{U} / \mathrm{ml}$ penicillin, and $100 \mu \mathrm{g} / \mathrm{ml}$ streptomycin (all from Gibco, Grand Island, NY, USA). PC12 cells were cultured in DMEM high-glucose supplemented with $10 \%$ horse serum and $5 \% \mathrm{FBS}, 100 \mathrm{U} / \mathrm{ml}$ penicillin, and $100 \mu \mathrm{g} / \mathrm{ml}$ streptomycin (all from Gibco). The cultures were maintained at $37^{\circ} \mathrm{C}$ under $5 \% \mathrm{CO}_{2}$.

Plasmid transfection. The cDNA fragment encoding the human DAPK1 or $\mathrm{DAPK} 1^{\mathrm{K} 42 \mathrm{~A}}$ mutant (in which lysine 42 was replaced by alanine) or DAPK $1^{\Delta \mathrm{CaM}}$ mutant (in which a $\mathrm{Ca}^{2+} /$ Calmodulin regulatory domain is deleted) was cloned into $5^{\prime}$-end-Flag tagged and CMV promoter-driven mammalian expression vector pRK5. The full-length cDNA of human WT tau or T231A (in which threonine 231 was replaced by alanine) tau or S262A (in which serine 262 was replaced by alanine) tau was cloned in the mammalian expression vector pcDNA3.1 vector (Invitrogen, Grand Island, NY, USA). Cells were transiently transfected with different plasmids using Lipofectamine 2000 (for HeLa, SH-SY5Y, SK-N-SH, and NIH3T3) or Lipofectamine LTX\&Plus (for MEF and PC12) transfection reagent (Invitrogen) according to the manufacturer's instruction. 
Lentiviral infection and si-RNA transfection. For generating stable DAPK1 knockdown SH-SY5Y cells, two DAPK1 sh-RNA clones, which are constructed within lentiviral pLKO.1-Puro vector were transfected together with VSV-G- and gag-pol-expressing plasmids into 293T cells. Sixty hours after transfection, virus-containing supernatants were used to infect the SH-SY5Y cells. A day after infection, the stable clones were selected using $1.5 \mu \mathrm{g} / \mathrm{ml}$ puromycin. The target sequences of DAPK1-specific sh-RNAs were as follows: sh-RNA-\#1, 5'-CAAGAAACGTTAGCAAATG-3'; sh-RNA-\#2, 5'-GGTCAAGGAT CCAAAGAAG-3'.

All si-RNAs were designed by Rosetta using a proprietary algorithm and were synthesized by Sigma. SH-SY5Y cells were transiently transfected with two different si-RNAs against human DAPK1 or scrambled si-RNA using Lipofectamine RNAiMAX Reagent (Invitrogen) according to the manufacturer's instructions. After $36 \mathrm{~h}$ of transfection, cells were harvested. For the neurite outgrowth assay, PC12 cells were also transiently transfected with a si-RNA against rat DAPK1 or scrambled si-RNA using Lipofectamine 2000 (Invitrogen) for $36 \mathrm{~h}$. The si-RNA target sequences were as follows: human DAPK1-\#1，5'-GAGAATCGATGTCCAGGA T-3'; human DAPK1-\#2, 5'-GACATGAAGGTACTTCGAA-3'; rat DAPK1, 5'-CC AACAACGGGATCCTAGA-3'; and scrambled si-RNA, 5'-GATCATACGTGCGA TCAGA-3'. A scrambled si-RNA has no identity to any known gene sequence from human, mouse, or rat in the BLAST database.

Quantitative RT-PCR assay for detection of the mRNA of tau and DAPK1. Total RNA was isolated from SH-SY5Y cells or tissues of human and mouse brain using an RNeasy Mini Kit or RNeasy Lipid Tissue Mini Kit (Qiagen, Valencia, CA, USA), respectively, according to the manufacturer's instructions. cDNAs were synthesized using the iScript CDNA synthesis kit (Bio-Rad, Hercules, CA, USA). To determine mRNA levels of tau and DAPK1, quantitative RT-PCR was performed on a Mastercycler ep realplex (Eppendorf, Hauppauge, NY, USA) using a total volume of $20 \mu$ containing $200 \mathrm{nM}$ primers and $1 \times$ AbsoluteTM Blue QPCR SYBR Green Mix (ABgene, Waltham, MA, USA). For human tau amplification, primers htau-F (5'-TGACACGG ACGCTGGCCTGAA-3') and htau-R (5'-CACTTGGAGGTCACCTTGCTC- $\left.3^{\prime}\right)$ were used. For human DAPK1 amplification, primers hDAPK1-F (5'-TCAAGACAGGC ACGGCAAT-3') and hDAPK1-R (5'-CCACCACGATAGGCATGTTG- $\left.3^{\prime}\right)$ were used. For human 36B4 amplification, primers h36B4-F (5'-AGATGCAGCAG ATCCGCAT- $3^{\prime}$ ) and h36B4-R (5'-GTTCTTGCCCATCAGCACC-3') were used. For human 18S rRNA amplification, primers h18S rRNA-F (5'-TGTCTCAAAGATT AAGCCATGCA-3') and h18S rRNA-R (GCGACCAAAGGAACCATAACTG-3') were used. For mouse tau amplification, primers mtau-F (5'-TTCT GTCCTCGCCTTCTGTC-3') and mtau-R (5'-CTCCAGCATGGTCTTCCATT-3') were used. For mouse 36B4 amplification, primers m36B4-F (5'-TTTGCTGTACTG ACTCGGTGA-3') and m36B4-R (5'-CCTCCCACAACAAAACAACC-3') were used.

Measurement of Tau protein stability in cell culture / tissue culture model. Tau protein half-life studies were performed by incubating cells or tissues with $\mathrm{CHX}(10-75 \mu \mathrm{g} / \mathrm{ml})$ for the indicated time. The exogenous tau protein stability was determined using HeLa, NIH3T3 carrying doxycyclineinducible expression of pTRE-Tight or pTRE-Tight-DAPK1, NIH3T3 carrying stably expressing Pin1 in combination with doxycycline-inducible expression of either pTRE-Tight or pTRE-Tight-DAPK1 or pTRE-Tight-DAPK1 ${ }^{\text {K42A }}$, WT MEF, DAPK1 KO MEF, and Pin1 KO MEF cells. The endogenous tau protein stability was determined using SK-N-SH cells and primary cortical neurons and brain slices prepared from WT and DAPK1 KO mice. The results from $\mathrm{CHX}$ experiments were quantified by densitometry and analyzed using the ImageQuant software.

Primary cortical neuronal cell cultures in mice. DAPK1 KO mice were described previously. ${ }^{57}$ Primary cultures of mouse embryonic cortical neurons were prepared as described previously. ${ }^{58,59}$ Briefly, dissociated embryonic neurons from embryonic day 16 (E16) WT and/or DAPK1 KO C57BL/6 pregnant mice were resuspended in minimal essential medium (Invitrogen) supplemented with 5\% FBS, 5\% horse serum, $100 \mu \mathrm{M}$ L-glutamine (Invitrogen), and $28 \mathrm{mM} \mathrm{D-glucose.} \mathrm{Cells} \mathrm{were} \mathrm{plated} \mathrm{onto} \mathrm{poly-D-lysine-coated}$ 6 -well plates and maintained in a serum-free medium system consisting of neurobasal media supplemented with B27 (Invitrogen) to inhibit glial proliferation. Cortical neuronal cells were used for assaying endogenous tau protein stability (at 1 week) and neurite outgrowth (at 3 days).

Organotypic brain-slice cultures. Organotypic mouse brain-slice cultures were performed as described previously ${ }^{38}$ with minor modifications.
Briefly, brains from 1- or 6-month-old mice were removed and cut into coronal slices of $260-\mu \mathrm{m}$ thickness with vibratome (Leica VT1200, Buffalo Grove, IL, USA). Slices containing the hippocampus were used for endogenous tau protein stability. The slices were cultured onto organotypic Millicell cell culture inserts (Millipore, Billerica, MA, USA) in 6-well culture plates with culture medium.

Extraction of sarkosyl-insoluble tau. A sarkosyl-insoluble fraction was prepared from mouse brain tissue as described previously ${ }^{38}$ with minor modification. The brain tissue was homogenized in $5 \times$ volume of ice-cold lysis buffer (10 mM Tris- $\mathrm{HCl}$ (pH 7.4), $0.8 \mathrm{M} \mathrm{NaCl}, 1 \mathrm{mM}$ EGTA, $10 \%$ sucrose, $1 \mathrm{mM}$ DTT) supplemented with protease inhibitor cocktail and phosphatase inhibitor cocktail and centrifuged at $20000 \times \mathrm{g}$ for $30 \mathrm{~min}$ at $4{ }^{\circ} \mathrm{C}$. The supernatant was collected and mixed to a final concentration of $1 \%(\mathrm{w} / \mathrm{v}) \mathrm{N}$-lauroylsarcosine and incubated for $1 \mathrm{~h}$ at room temperature with constant shaking. After ultracentrifugation at $100000 \times g$ for $1 \mathrm{~h}$ at $4{ }^{\circ} \mathrm{C}$, the pellet containing sarkosylinsoluble, aggregated tau was resuspended in $50 \mathrm{mM}$ Tris- $\mathrm{HCl}(\mathrm{pH} 7.4)$ and analyzed by SDS-polyacrylamide gel electrophoresis (PAGE) for quantification of phosphorylated tau protein.

Immunohistochemical detection of phosphorylation of tau and Pin1. For immunohistochemical analysis of mouse brain tissues, WT and DAPK1 KO mice were anesthetized and intracardially perfused with 4\% PFA. Immersion-fixed tissue sections were embedded in paraffin. Coronal tissue sections were deparaffinized with xylene, rehydrated with descending grade of ethanol, and incubated with $3 \% \mathrm{H}_{2} \mathrm{O}_{2} / \mathrm{PBS}$ to quench the endogenous peroxidase activity. After antigen retrieval, sections were incubated in PBS blocking buffer with $5 \%$ horse serum, $5 \%$ bovine serum albumin and $0.1 \% \mathrm{v} / \mathrm{v}$ Tween 20 . Primary antibodies were added in blocking buffer and incubated with sections overnight at $4{ }^{\circ} \mathrm{C}$. Secondary antibody was biotinylated goat-anti-rabbit IgG. Sections were processed with $A B C$ reagents by using a Vector $A B C$ kit (Vector Laboratories, Burlingame, CA, USA). After washing, the horseradish peroxidase (HRP) reaction was detected with diaminobenzidine and $\mathrm{H}_{2} \mathrm{O}_{2}$. Positively stained areas were quantified with ImageJ software.

Neurite outgrowth assay. To induce differentiation, $\mathrm{PC} 12$ cells plated onto poly-L-lysine (Sigma)-coated 6-well in serum starved conditions $(0.5 \%$ horse serum and $0.25 \% \mathrm{FBS}$ ) were treated with $50 \mathrm{ng} / \mathrm{ml}$ NGF. Once cells developed neurites after induction of differentiation, cells were fixed with 4\% PFA for $15 \mathrm{~min}$ at room temperature. The level of neurite outgrowth was quantified by counting the number of PC12 cells bearing at least one neurite with a length equal to the cell body diameter and by measuring the neurite length in random images from triplicate experiments. Neurites were categorized by their length relative to the cell body diameter as previously described. ${ }^{60}$ ' $L 0$ ' means cells with no neurite, 'L1' means cells with neurites whose length is shorter than the cell body diameter, 'L2' means cells with neurites whose length is between the original and twice the cell body diameter, and ' $\mathrm{L} 3$ ' means cells with neurites whose length is longer than twice the cell body diameter.

In vivo MT assembly assay. $\mathrm{PC} 12$ cells were exposed to paclitaxel $(0.2 \mu \mathrm{M})$, nocodazole $(2 \mu \mathrm{M})$, and DAPK1 inhibitor $(70-, 100 \mathrm{nM})$ for $12 \mathrm{~h}$. After treatment, cells were harvested and lysed at $37^{\circ} \mathrm{C}$ for $5 \mathrm{~min}$ with hypotonic buffer (1 $\mathrm{mM} \mathrm{MgCl}_{2}, 2 \mathrm{mM}$ EGTA, 0.5\% NP-40, $20 \mathrm{mM}$ Tris- $\mathrm{HCl}$ (pH 6.8)) supplemented with protease inhibitor cocktail. The cell lysates were centrifuged at $18000 \times g$ for $10 \mathrm{~min}$ at $25^{\circ} \mathrm{C}$. The supernatants containing the unpolymerized (soluble) tubulin were transferred to a fresh tube. The pellets containing the polymerized (insoluble) tubulin were resuspended in an equal amount of hypotonic buffer and sonicated on ice for $2 \mathrm{~min}$. Protein samples $(10 \mu \mathrm{g})$ of the two fractions were separated by SDS-PAGE. The tubulin signals were quantified by densitometry and analyzed using the ImageQuant software.

Immunoblot analysis. After harvesting, the cells were lysed in ice-cold lysis buffer (50 mM Tris- $\mathrm{HCl}(\mathrm{pH} 7.4), 50 \mathrm{mM} \mathrm{NaCl}, 1 \mathrm{mM}$ EGTA, $1 \%$ Triton X-100, $1 \mathrm{mM}$ DTT) supplemented with protease inhibitor cocktail and phosphatase inhibitor cocktail. Mouse and human brain extracts were prepared by homogenizing tissue in ice-cold lysis buffer (10 mM Tris- $\mathrm{HCl}(\mathrm{pH} 7.4), 0.8 \mathrm{M}$ $\mathrm{NaCl}, 1 \mathrm{mM}$ EGTA, 10\% sucrose, $1 \mathrm{mM}$ DTT) supplemented with protease inhibitor cocktail and phosphatase inhibitor cocktail. The soluble protein concentration was determined by Bradford assay (Bio-Rad). Protein samples $(5-10 \mu \mathrm{g})$ were separated by SDS-PAGE and transferred to polyvinylidene fluoride 
membranes (PerkinElmer, Waltham, MA, USA). The membranes were then probed with various antibodies, followed by HRP-conjugated secondary antibodies. Antibody-bound proteins were detected using the Western Lightning Plus-ECL (PerkinElmer) or ECL Prime (GE Healthcare Life Sciences, Pittsburgh, PA, USA) chemiluminescence system. The following antibodies were used to probe different proteins: Flag, DAPK1 (Sigma); DCX, $\beta$-actin, $\alpha$-tubulin (Cell Signaling Technology, Danvers, MA, USA); PHF-13 (p-Ser396-Tau) (Anaspec, Fremont, CA, USA); Tau-5, p-Tau (Ser262); and AT180 (pThr231-Tau) (Invitrogen).

Brain samples. Whole-brain tissues from mice at different ages (1-22 month) were harvested for the comparison between WT and DAPK1 KO littermates. After extraction, whole brains were snap frozen in liquid nitrogen-cold isopentane and stored at $-80^{\circ} \mathrm{C}$ until use. Total brain lysates and sarkosyl-insoluble fractions were obtained from these mouse brain tissues. Brain hippocampus tissues of human Alzheimer's patients and controls were obtained from the Neuropathology Core of the Massachusetts Alzheimer's Disease Research Center (Boston, MA, USA) and the Harvard Brain Tissue Resource Center (Boston, MA, USA). Research was conducted in compliance with the policies and principles contained in the Federal Policy for the Protection of Human subjects. In most cases, brain hippocampus tissues obtained within $30 \mathrm{~h}$ postmortem were used; 12 from individuals with a clinical diagnosis of probable $A D$ and 12 from individual without any neurological disorder (Supplementary Table S1).

Statistical analysis. The data are presented as means \pm standard error (S.E.) of the three independent experiments. Statistical significances were calculated by one-way analysis of variance (ANOVA) followed by Dunnett's multiple comparison post hoc test using SAS 8.1 software for Windows (SAS Institute), with $P$-values $<0.05$ considered to be statistically significant.

Study approval. All studies were carried out following the guidelines set by Beth Israel Deaconess Medical Center's Institutional Animal Care and Use Committee in accordance with the Association for Assessment and Accreditation of Laboratory Animal Care International regulations.

\section{Conflict of Interest}

The authors declare no conflict of interest.

Acknowledgements. We thank Kun Ping Lu (Harvard Medical School, Boston, MA, USA) for his expert advice and critical reading of the manuscript. Human brain tissues were provided by the Neuropathology Core of the Massachusetts Alzheimer Disease Research Center (P50AG05134) and the Harvard Brain Tissue Resources Center (R24MH068855). BM Kim is the recipient of the National Research Foundation (NRF-2011-356-C00085). C-H Chen is the recipient of a Ruth L. Kirschstein National Research Service Award (T32AG023480). This work was supported by a grant from the Inje Research and Scholarship Foundation to Y Hong and NIH grant (R00AG033104), the Alzheimer's Association (NIRG-12-258863) and the American Federation for Aging Research to TH Lee.

1. Ballatore C, Lee VM, Trojanowski JQ. Tau-mediated neurodegeneration in Alzheimer's disease and related disorders. Nat Rev Neurosci 2007; 8: 663-672.

2. Goedert M, Spillantini MG. A century of Alzheimer's disease. Science 2006; 314: 777-781.

3. Mattson MP. Pathways towards and away from Alzheimer's disease. Nature 2004; 430 : 631-639.

4. Spires-Jones TL, Stoothoff WH, de Calignon A, Jones PB, Hyman BT. Tau pathophysiology in neurodegeneration: a tangled issue. Trends Neurosci 2009; 32 : 150-159.

5. Lee VM, Balin BJ, Otvos Jr L, Trojanowski JQ. A68: a major subunit of paired helica filaments and derivatized forms of normal Tau. Science 1991; 251: 675-678.

6. Goedert M, Spillantini MG, Cairns NJ, Crowther RA. Tau proteins of Alzheimer paired helical filaments: abnormal phosphorylation of all six brain isoforms. Neuron 1992; 8 : 159-168

7. Matsuo ES, Shin RW, Billingsley ML, Van deVoorde A, O'Connor M, Trojanowski JQ et al. Biopsy-derived adult human brain tau is phosphorylated at many of the same sites as Alzheimer's disease paired helical filament tau. Neuron 1994; 13: 989-1002.

8. Drubin DG, Feinstein SC, Shooter EM, Kirschner MW. Nerve growth factor-induced neurite outgrowth in $\mathrm{PC} 12$ cells involves the coordinate induction of microtubule assembly and assembly-promoting factors. J Cell Biol 1985; 101(5 Pt 1): 1799-1807.
9. Lee $\mathrm{G}$, Cowan N, Kirschner M. The primary structure and heterogeneity of tau protein from mouse brain. Science 1988; 239: 285-288.

10. Lee G, Neve RL, Kosik KS. The microtubule binding domain of tau protein. Neuron 1989; 2: 1615-1624.

11. Esmaeli-Azad B, McCarty JH, Feinstein SC. Sense and antisense transfection analysis of tau function: tau influences net microtubule assembly, neurite outgrowth and neuritic stability. J Cell Sci 1994; 107(Pt 4): 869-879.

12. Bramblett GT, Goedert M, Jakes R, Merrick SE, Trojanowski JQ, Lee VM. Abnormal tau phosphorylation at Ser396 in Alzheimer's disease recapitulates development and contributes to reduced microtubule binding. Neuron 1993; 10: 1089-1099.

13. Iqbal K, Zaidi T, Bancher C, Grundke-lqbal I. Alzheimer paired helical filaments Restoration of the biological activity by dephosphorylation. FEBS Lett 1994; 349: 104-108.

14. Stoothoff WH, Johnson GV. Tau phosphorylation: physiological and pathological consequences. Biochim Biophys Acta 2005; 1739: 280-297.

15. Poppek D, Keck S, Ermak G, Jung T, Stolzing A, Ullrich O et al. Phosphorylation inhibits turnover of the tau protein by the proteasome: influence of RCAN1 and oxidative stress. Biochem J 2006; 400: 511-520.

16. Petrucelli L, Dickson D, Kehoe K, Taylor J, Snyder H, Grover A et al. CHIP and Hsp70 regulate tau ubiquitination, degradation and aggregation. Hum Mol Genet 2004; 13: 703-714

17. Kosik KS, Shimura H. Phosphorylated tau and the neurodegenerative foldopathies. Biochim Biophys Acta 2005; 1739: 298-310.

18. Dickey CA, Kamal A, Lundgren K, Klosak N, Bailey RM, Dunmore J et al. The high-affinity HSP90-CHIP complex recognizes and selectively degrades phosphorylated tau client proteins. J Clin Invest 2007; 117: 648-658.

19. Green KN, Steffan JS, Martinez-Coria H, Sun X, Schreiber SS, Thompson LM et al. Nicotinamide restores cognition in Alzheimer's disease transgenic mice via a mechanism involving sirtuin inhibition and selective reduction of Thr231-phosphotau. J Neurosci 2008; 28: $11500-11510$.

20. Illenberger S, Zheng-Fischhofer Q, Preuss U, Stamer K, Baumann K, Trinczek B et al. The endogenous and cell cycle-dependent phosphorylation of tau protein in living cells: implications for Alzheimer's disease. Mol Biol Cell 1998; 9: 1495-1512.

21. Pelech SL. Networking with proline-directed protein kinases implicated in tau phosphorylation. Neurobiol Aging 1995; 16: 247-256; discussion 257-261.

22. Dolan PJ, Johnson GV. The role of tau kinases in Alzheimer's disease. Curr Opin Drug Discov Devel 2010; 13: 595-603.

23. Goedert M, Satumtira S, Jakes R, Smith MJ, Kamibayashi C, White 3rd CL et al. Reduced binding of protein phosphatase $2 \mathrm{~A}$ to tau protein with frontotemporal dementia and parkinsonism linked to chromosome 17 mutations. J Neurochem 2000; 75: 2155-2162.

24. Sontag E, Nunbhakdi-Craig V, Lee G, Bloom GS, Mumby MC. Regulation of the phosphorylation state and microtubule-binding activity of Tau by protein phosphatase $2 \mathrm{~A}$. Neuron 1996; 17: 1201-1207.

25. Patrick GN, Zukerberg L, Nikolic M, de la Monte S, Dikkes P, Tsai LH. Conversion of p35 to p25 deregulates Cdk5 activity and promotes neurodegeneration. Nature 1999; 402: 615-622.

26. Noble W, Olm V, Takata K, Casey E, Mary O, Meyerson J et al. Cdk5 is a key factor in tau aggregation and tangle formation in vivo. Neuron 2003; 38: 555-565.

27. Cruz JC, Tseng HC, Goldman JA, Shih H, Tsai LH. Aberrant Cdk5 activation by p25 triggers pathological events leading to neurodegeneration and neurofibrillary tangles. Neuron 2003; 40: 471-483.

28. Bialik S, Kimchi A. The death-associated protein kinases: structure, function, and beyond. Annu Rev Biochem 2006; 75: 189-210.

29. Wu PR, Tsai PI, Chen GC, Chou HJ, Huang YP, Chen YH et al. DAPK activates MARK1/2 to regulate microtubule assembly, neuronal differentiation, and tau toxicity. Cell Death Differ 2011; 18: 1507-1520.

30. Tu W, Xu X, Peng L, Zhong X, Zhang W, Soundarapandian MM et al. DAPK1 interaction with NMDA receptor NR2B subunits mediates brain damage in stroke. Cell 2010; 140: 222-234

31. Li Y, Grupe A, Rowland C, Nowotny P, Kauwe JS, Smemo S et al. DAPK1 variants are associated with Alzheimer's disease and allele-specific expression. Hum Mol Genet 2006; 15: 2560-2568.

32. Li H, Wetten S, Li St L, Jean PL, Upmanyu R, Surh L et al. Candidate single-nucleotide polymorphisms from a genomewide association study of Alzheimer disease. Arch Neurol 2008; 65: 45-53.

33. Yukawa K, Tanaka T, Bai T, Li L, Tsubota Y, Owada-Makabe K et al. Deletion of the kinase domain from death-associated protein kinase enhances spatial memory in mice. Int $\mathrm{J} \mathrm{Mol}$ Med 2006; 17: 869-873

34. Lee TH, Chen CH, Suizu F, Huang P, Schiene-Fischer C, Daum S et al. Death-associated protein kinase 1 phosphorylates Pin1 and inhibits its prolyl isomerase activity and cellular function. Mol Cell 2011; 42: 147-159.

35. Lu KP, Zhou XZ. The prolyl isomerase PIN1: a pivotal new twist in phosphorylation signalling and disease. Nat Rev Mol Cell Biol 2007; 8: 904-916.

36. Lee TH, Pastorino L, Lu KP. Peptidyl-prolyl cis-trans isomerase Pin1 in ageing, cancer and Alzheimer disease. Expert Rev Mol Med 2011; 13: e21.

37. Liou Y-C, Sun A, Ryo A, Zhou XZ, Yu Z-X, Huang H-K et al. Role of the prolyl isomerase Pin1 in protecting against age-dependent neurodegeneration. Nature 2003; 424: 556-561. 
38. Lim J, Balastik M, Lee TH, Liou Y-C, Sun A, Finn G et al. Pin1 has opposite effects on wildtype and P301L tau stability and tauopathy. J Clin Invest 2008; 118: 1877-1889.

39. Pastorino L, Sun A, Lu PJ, Zhou XZ, Balastik M, Finn G et al. The prolyl isomerase Pin regulates amyloid precursor protein processing and amyloid-beta production. Nature 2006; 440: 528-534.

40. Lu PJ, Wulf G, Zhou XZ, Davies P, Lu KP. The prolyl isomerase Pin1 restores the function of Alzheimer-associated phosphorylated tau protein. Nature 1999; 399: 784-788.

41. Ramakrishnan P, Dickson DW, Davies P. Pin1 colocalization with phosphorylated tau in Alzheimer's disease and other tauopathies. Neurobiol Dis 2003; 14: 251-264.

42. Yamamoto $M$, Takahashi $\mathrm{H}$, Nakamura $\mathrm{T}$, Hioki $\mathrm{T}$, Nagayama $\mathrm{S}$, Ooashi $\mathrm{N}$ et al. Developmental changes in distribution of death-associated protein kinase mRNAs. J Neurosci Res 1999; 58: 674-683.

43. Buerger K, Zinkowski R, Teipel SJ, Tapiola T, Arai H, Blennow K et al. Differential diagnosis of Alzheimer disease with cerebrospinal fluid levels of tau protein phosphorylated at threonine 231. Arch Neurol 2002; 59: 1267-1272.

44. Raveh T, Droguett G, Horwitz MS, DePinho RA, Kimchi A. DAP kinase activates a p19ARF/p53-mediated apoptotic checkpoint to suppress oncogenic transformation. Nat Cell Biol 2001; 3: 1-7.

45. Mandell JW, Banker GA. Microtubule-associated proteins, phosphorylation gradients, and the establishment of neuronal polarity. Perspect Dev Neurobiol 1996; 4: 125-135.

46. Johnson GV, Stoothoff WH. Tau phosphorylation in neuronal cell function and dysfunction. Journal Cell Sci 2004; 117(Pt 24): 5721-5729.

47. Rosengren LE, Karlsson JE, Karlsson JO, Persson LI, Wikkelso C. Patients with amyotrophic lateral sclerosis and other neurodegenerative diseases have increased levels of neurofilament protein in CSF. J Neurochemistry 1996; 67: 2013-2018.

48. Rosengren LE, Karlsson JE, Sjogren M, Blennow K, Wallin A. Neurofilament protein levels in CSF are increased in dementia. Neurology 1999; 52: 1090-1093.

49. Sze Cl, Su M, Pugazhenthi S, Jambal P, Hsu LJ, Heath J et al. Down-regulation of WW domain-containing oxidoreductase induces Tau phosphorylation in vitro. A potential role in Alzheimer's disease. J Biol Chem 2004; 279: 30498-30506.

50. Ferrer I, Barrachina M, Puig B, Martinez de Lagran M, Marti E, Avila J et al. Constitutive Dyrk1A is abnormally expressed in Alzheimer disease, Down syndrome, Pick disease, and related transgenic models. Neurobiol Dis 2005; 20: 392-400.

51. Santa-Maria I, Varghese M, Ksiezak-Reding H, Dzhun A, Wang J, Pasinetti GM. Paired helical filaments from Alzheimer disease brain induce intracellular accumulation of Tau protein in aggresomes. J Biol Chem 2012; 287: 20522-20533.
52. Avila J, Lucas JJ, Perez M, Hernandez F. Role of tau protein in both physiological and pathological conditions. Physiol Rev 2004; 84: 361-384.

53. Ebneth A, Drewes G, Mandelkow EM, Mandelkow E. Phosphorylation of MAP2c and MAP4 by MARK kinases leads to the destabilization of microtubules in cells. Cell Motil Cytoskeleton 1999; 44: 209-224.

54. Kojima Y, Miyoshi H, Clevers HC, Oshima M, Aoki M, Taketo MM. Suppression of tubulin polymerization by the LKB1-microtubule-associated protein/microtubule affinity-regulating kinase signaling. J Biol Chem 2007; 282: 23532-23540.

55. Lauckner J, Frey P, Geula C. Comparative distribution of tau phosphorylated at Ser262 in pre-tangles and tangles. Neurobiol Aging 2003; 24: 767-776.

56. Gu GJ, Wu D, Lund H, Sunnemark D, Kvist AJ, Milner R et al. Elevated MARK2-dependent phosphorylation of Tau in Alzheimer's disease. J Alzheimers Dis 2013; 33: 699-713.

57. Gozuacik D, Bialik S, Raveh T, Mitou G, Shohat G, Sabanay H et al. DAP-kinase is a mediator of endoplasmic reticulum stress-induced caspase activation and autophagic cell death. Cell Death Differ 2008; 15: 1875-1886.

58. Niethammer M, Smith DS, Ayala R, Peng J, Ko J, Lee MS et al. NUDEL is a novel Cdk5 substrate that associates with LIS1 and cytoplasmic dynein. Neuron 2000; 28: 697-711.

59. Saha RN, Ghosh A, Palencia CA, Fung YK, Dudek SM, Pahan K. TNF-alpha preconditioning protects neurons via neuron-specific up-regulation of CREB-binding protein. J Immunol 2009; 183: 2068-2078.

60. Kim JA, Lee N, Kim BH, Rhee WJ, Yoon S, Hyeon T et al. Enhancement of neurite outgrowth in PC12 cells by iron oxide nanoparticles. Biomaterials 2011; 32: 2871-2877.

(i) $(-)$ Cell Death and Disease is an open-access journal published by Nature Publishing Group. This work is licensed under a Creative Commons Attribution-NonCommercialNoDerivs 3.0 Unported License. The images or other third party material in this article are included in the article's Creative Commons license, unless indicated otherwise in the credit line; if the material is not included under the Creative Commons license, users will need to obtain permission from the license holder to reproduce the material. To view a copy of this license, visit http://creativecommons.org/ licenses/by-nc-nd/3.0/

Supplementary Information accompanies this paper on Cell Death and Disease website (http://www.nature.com/cddis) 